\section{E- LOGOS}

ELECTRONIC JOURNAL FOR PHILOSOPHY ISSN 1211-0442

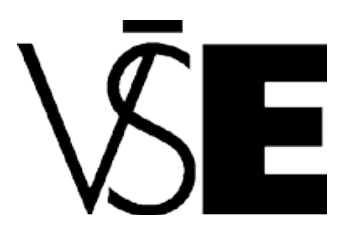

University of Economics

Prague

\title{
About a logic of measurability
}

Arto Mutanen

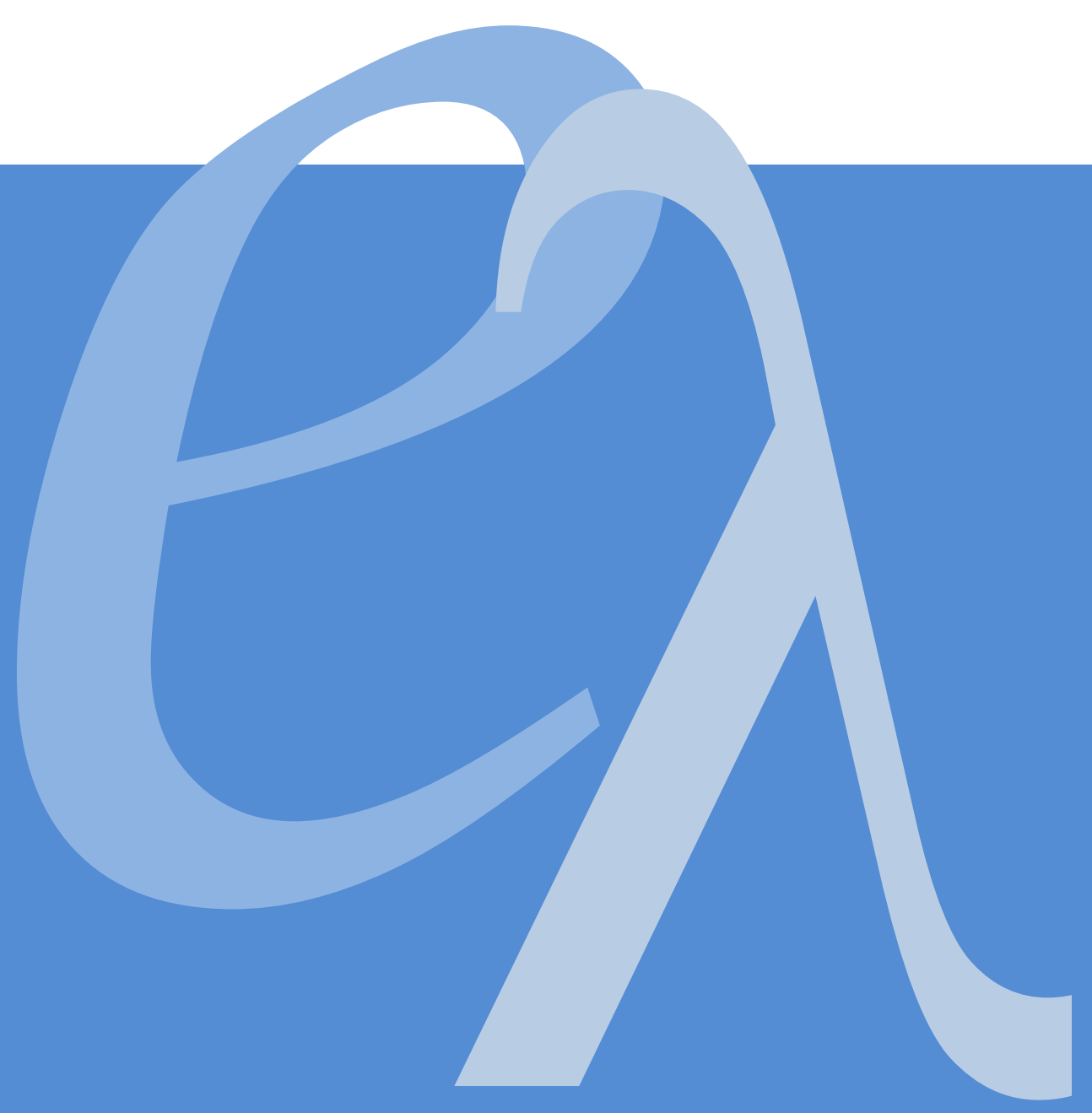




\section{Abstract}

The notion of measurability is of central importance in empirical sciences. However, the general logic of measurability is not clear enough. In the present paper we will consider a logic of measurability. The intention is to get a notion of measurability which would have some general properties that the notion of measurability should have. The general strategy is to interconnect the logic of measurability to more general logic of experimental sciences. This gives us a logic of measurability which have several general properties that the notion of measurability is assumed to have. This will show that the strategy of the paper is of more general philosophical importance. 


\section{Introduction}

The work of scientists is to conduct scientific research. A scientist starts as a student and eventually becomes a competent scientist. There are several different kinds of fields of science, and each field of science has several different kinds of approaches. So, to say something general about scientific research is not an easy task. However, this is the task of a philosopher of science. To complete this task, one strategy is to take some specific topic and say something general about it, hoping that this throws some light on research work in general. In this paper, we take up this strategy. The specific topic is the notion of measurability. The notion is of central importance in different fields of science. Moreover, the meaning of the notion obviously varies from case to case. There is a proper need for a general conceptual and methodological consideration of the notion which would throw a little light on the different but interconnected meanings of the notion. To accomplish this task we will consider the notion within a general philosophical framework. This allows us to get a general methodological picture of the notion of measurability and its role in the scientific research process.

The notion of measurability is related to the notions of observation, testing a theory, and prediction. Measurement involves the experimental determination of a quantity and determining the scale of the quantity. (Suppe 1989) The general problem is that the reference point of the measurement is in physical reality and the observations on which the measurement rests are at the phenomenal level. The problem is, how can we guarantee that the measurement is about physical reality, and not only about the phenomenon we are basically interested in. In the following, our approach is philosophical. This allows us to see the general logic of measurement. Hence, our approach allows us to consider the general philosophical problems referred to.

\section{Notion of observation}

In empirical science observation plays an essential role. Basically, observation is used in testing or confirming a theory. In the following, we will consider the role of observation also in the measuring process. Visual observation involves attending to something in a manner which essentially involves seeing, so as to obtain information that something is the case. In this paper we try to find out some logical properties of observation. The intention is to throw light on the logic of measurement. Our approach is philosophico-conceptual, and hence it is of a general character. However, because of this generality, the applicability of the observations we make is very wide - in particular, they will apply to visual observation as well as to observation generally. (See Suppe 1989, Hintikka 2007) 
We can see the moons of Jupiter with an optical telescope, but we cannot see pulsars with them. To see pulsars we need radio telescopes. Similarly, we need some special observational technology to see electrons. So observation, and observability, depend on the level of observational and experimental technology.

We can see with naked eyes that 'steam is issuing from the kettle'. In this case we say that we make a direct observation. But if we see that 'water is boiling in the kettle' by directly seeing that 'steam is issuing from the kettle', we say that we make an indirect observation. Unfortunately, this distinction is not clear cut. (Suppe 1989) For example, one problem is what kind of technology we may use in direct observation. If I have glasses, do I then see directly or indirectly?

It is clear that in science observation may include inferences. But inferences may not be included without restrictions. If we see that $p$ by seeing that $q$, there is the problem of what kind of inferences we may use in deducing p from q. Suppe (1989) says that "inferences allowed in observing that $\varphi$ must be restricted to inferences from $\psi$ to $\varphi$, where one sees that $\psi$ and where $\psi$ and known collateral information $\chi$ entails that $\varphi^{\prime \prime}$.

To analyse these points, we use Hintikka's notions of the interrogative model of inquiry and identifiability. These notions make it possible to analyse the relation between seeing and inferring in an explicit way. We will show that the notion of identifiability can be seen as an explication of the notion of measurability. In the following we give a short explication of these notions. (See Hintikka 1991, 2007, Hintikka, Halonen and Mutanen 2002, Mutanen 1997, 2004)

\section{Interrogative derivability}

Professor Jaakko Hintikka has developed a general model of scientific inquiry. The model is called the interrogative model of inquiry. The very basic idea behind the model is extremely simple: a scientist searches for knowledge by asking questions. However, even if the model has such a simple basic idea, it has several interesting logical and philosophical implications. First, it has deep philosophical roots that start from the Socratic questioning method and continue to the present day logical theories of questions. (Hintikka, Halonen and Mutanen 2002, Hintikka 2007, Sintonen 2006) In this paper we will not explicate the model more precisely; we will only explicate the logical notion of interrogative derivability, which shows the philosophical importance of the model. Even if the proofs of the results can be found from the references mentioned below, we will provide them here. The reason for this is that the proof shows explicitly how the information needed is constructed and explicated. Thus, the proofs explicate why the interrogative model can be called a constructive methodology. Moreover, the proofs show why the constructivity is an argument not against realism but for realism. (See Hintikka 2007, Hacking 1999) 
The notation we will use is the standard notation of mathematical logic. We assume that the reader is capable of reading the notation. Let $\mathrm{L}$ be a first order language and let $\mathrm{L}(\mathrm{P})$ be the extension of $\mathrm{L}$ with one-place predicate symbol $\mathrm{P}$. We denote other extensions of the language L similarly. Let $T(P)$ be a theory in $L(P)$ and let $\mathbf{A}$ be any infinite model of the language of the underlying theory $\mathrm{T}(\mathrm{P})$. So, $\mathbf{A}=$ $\mathrm{T}(\mathrm{P})$. (For further information see, for example, Hodges 1993 and Hintikka 1988, 1991, 1992.)

Let $\mathrm{F}$ be a formula of $\mathrm{L}(\mathrm{P})$. We say that $\mathrm{F}$ can be interrogatively derived from $T(P)$ in $A$, if we can deduce $\mathrm{F}$ from $\mathrm{T}(\mathrm{P})$ together with some auxiliary information from the model A. We denote this by the following formula

(1) A:T(P) ト F.

It is interesting to note that the notion of interrogative derivability lies between the notions of usual derivability and truth in a model. If we do not use any information from the model, then (1) reduces to the usual deduction:

(2) $\mathrm{T}(\mathrm{P})$ - F.

If there is no restriction on the information that we can get from the model $\mathbf{A}$, then (1) reduces to the truth in the model:

(3) $\mathrm{A} \vDash \mathrm{F}$.

Restrictions concerning the available information from the model must be spelled out. This is partly a pragmatic problem, and it will be done separately for every case. It is quite interesting that these results hold largely independently of what restrictions are imposed on this information, as long as it remains constant throughout the argument. Information from the model consists of names of individuals from the domain of the model, and it can be expressed in the extended language $\mathrm{L}(\mathrm{P}, \mathrm{A})$ (or $\mathrm{L}(\mathrm{A})$ if $\mathrm{P}$ does not occur in it). Let $\mathrm{K}$ be a set of sentences that includes all the available information from the model $\mathbf{A}$. In this case (1) reduces to

(4) $T(P) \cup K \vdash F$.

(See, Hintikka, Halonen and Mutanen 2002.) 


\section{Identifiability}

Let $\mathbf{A}$ be a model of $\mathrm{T}(\mathrm{P})$. We say that $\mathrm{P}$ is explicitly identifiable on the basis of $\mathrm{T}(\mathrm{P})$ in $\mathbf{A}$ iff $\mathrm{T}(\mathrm{P})$ together with some auxiliary information from the model $\mathbf{A}$ implies a quasidefinition of the following form

(5) $\forall x\left[\mathrm{Px}<->\mathrm{D}\left(\mathrm{x}, \mathrm{a}_{1}, \ldots, \mathrm{a}_{\mathrm{n}}\right)\right]$,

where $\mathrm{D}\left(\mathrm{x}, \mathrm{y}_{1}, \ldots, \mathrm{y}_{\mathrm{n}}\right)$ is a formula of $\mathrm{L}$ and $\mathrm{a}_{1}, \ldots, \mathrm{a}_{\mathrm{n}} \varepsilon \mathrm{A}$ (domain of $\mathrm{A}$ ), and of course the auxiliary information may not contain $P$. If (5) holds in every model of $T(P)$, then we say that $P$ is explicitly identifiable in every model of T(P). (Mutanen 1997)

So if $\mathrm{P}$ is explicitly identifiable on the basis of $\mathrm{T}(\mathrm{P})$ in $\mathbf{A}$ then it is definable in the extended model $\left(\mathbf{A}, \mathrm{a}_{1}, \ldots, \mathrm{a}_{\mathrm{n}}\right)$ where $\mathrm{a}_{1}, \ldots, \mathrm{a}_{\mathrm{n}}$ are new distinguished individuals. If $\mathrm{P}$ is explicitly identifiable on the basis of $\mathrm{T}(\mathrm{P})$ in every model of $\mathrm{T}(\mathrm{P})$, then $\mathrm{P}$ is explicitly or piecewise definable in the extended language $L\left(c_{1}, \ldots, c_{n}\right)$, where $c_{1}, \ldots, c_{n}$ are new constants. This shows how easy it is to confuse identifiability with definability. (See Mutanen 2004)

The notions of definability and identifiability are different but closely related. The historical roots of the notion of definability are in logic and the historical roots of the notion of identifiability are in econometrics. However, in the methodology the use of the two notions has not been very clear: in philosophy of science the notion of definability is often used even if the notion of identifiability would be correct. (Rantala 1991)

We say that $\mathrm{P}$ is implicitly identifiable on the basis of $\mathrm{T}(\mathrm{P})$ in $\mathbf{A}$ iff for each individual a from A either

(6) $\mathrm{A}: \mathrm{T}(\mathrm{P}) \vdash \mathrm{Pa}$ or

(7) $\mathbf{A}: \mathrm{T}(\mathrm{P}) \vdash \sim \mathrm{Pa}$,

where the auxiliary information from the model A may not contain P. (Hintikka 1991, Rantala 1977, Mutanen 1997)

The notion of implicit identification is closely connected to the notion of observation. However, to see the connection more precisely, let us consider the logic of identification and the logic of observation more closely. 


\section{Logic of identification}

Let $\mathrm{Pa}$ be a proposition such that a refers to an individual from A (the domain of the model A). We say that we can simply observe that the case is Pa if we can see (by naked eye) that $\mathrm{Pa}$. It should be noticed that the notion of observation is dependent on the environment A. The structure of the simple observation is complex; in fact, it reminds us closely of the structure of identification. (Alston 1993, Mutanen 2003, 2004) The simple observation of Pa we denote by following formula

(8) A 怗Pa.

The symbol ' $\mid$ ' refers to simple observability. It is closely related to the truth in a model. If our observations would be all true then $\mathbf{A} \mid$ i Pa implies A F Pa. However, the converse does not in general hold: not all the truths are observable. Moreover, it must be emphasized that in simple observation one is not inferring in the usual (logical) sense, which is emphasized in the notation. In observation, one is just observing, even if the analysis of observation can be structurally similar as in epistemic logic. (Niiniluoto 1982) Similarly, if we simply observe that $\sim \mathrm{Pa}$, we denote this by the following formula

(9) $\mathbf{A} \| \sim \mathrm{Pa}$.

For example, if $\mathrm{Px}$ is 'individual $\mathrm{x}$ has the property of being red', then 'Pa' means that 'individual a has the property of being red', and formula (8) means that 'I (the observer) can see that a has the property of being red'. Notice that direct observation is in a sense positive; one sees that something is red. From this he or she can infer that it is not blue. Negative observation needs its own consideration. (Mutanen 2003)

We define sets $\Gamma^{+}, \Gamma^{-}$and $\Gamma$ in the following way:

$$
\begin{aligned}
& \Gamma^{+}=\left\{\mathrm{a} \varepsilon \mathrm{A}: \mathbf{A} \mathbb{\Gamma}_{\Gamma} \mathrm{Pa}\right\}, \\
& \Gamma^{-}=\left\{\mathrm{a} \varepsilon \mathrm{A}: \mathbf{A} \mid \Gamma^{-} \sim \mathrm{Pa}\right\} \text { and } \\
& \Gamma=\left\{\mathrm{a} \varepsilon \mathrm{A}: \mathrm{a} \notin \Gamma^{+} \text {and } \mathrm{a} \notin \Gamma^{-}\right\} .
\end{aligned}
$$


If a $\varepsilon \Gamma^{+}$, then we can see that $\mathrm{Pa}$; if a $\varepsilon \Gamma^{-}$, then we can see that $\sim \mathrm{Pa}$; and if a $\varepsilon \Gamma$, then we cannot see whether the case is $\mathrm{Pa}$ or $\sim \mathrm{Pa}$. We say that $\Gamma^{+}$is the P-positive set, $\Gamma^{-}$is the P-negative set and $\Gamma$ is the uncertainty set. We can easily see that the sets $\Gamma^{+}, \Gamma^{-}$ and $\Gamma$ are mutually exclusive and jointly exhaustive. We say that predicate $P$ is simply observable in $A$ if $\Gamma=\varnothing$. Unfortunately, usually this is not the case. (More precisely, see Rantala 1977 and Alston 1993)

Let the uncertainty set $\Gamma$ be non-empty, and let a be an individual in $\Gamma$. Now we need some further information to decide whether it is the case that $\mathrm{Pa}$ or $\sim \mathrm{Pa}$. This further information may include some observational or experimental technology or some theoretical generalizations. This means that the observations may include measurements or inferences. (See Hintikka 1992.) Let this further information be a theory $\mathrm{T}(\mathrm{P})$. If the case is $\mathrm{Pa}$, we can derive $\mathrm{Pa}$ interrogatively from $\mathrm{T}(\mathrm{P})$ in $\mathbf{A}$, so we have the following formula

(10) A:T(P) ト Pa.

In this case we can say that the observation of $\mathrm{Pa}$ is $T(P)$-dependent. (Hintikka 1992) If the case is $\sim \mathrm{Pa}$, we have similar results. Here, the theory is mentioned explicitly. Moreover, by analyzing the actual interrogative deduction (10) we can see explicitly in what sense the observation is dependent on the theory. (Hintikka, Halonen and Mutanen 2002, see also Hacking 1983.)

We can easily define the P-positive, P-negative and uncertainty sets also in this generalized case. So, for example, the P-positive set relative to $T(P)$ is the set of individuals a such that $\mathrm{Pa}$ can be interrogatively derived from $\mathrm{T}(\mathrm{P})$ in $\mathbf{A}$, i.e.

$$
\begin{aligned}
& \Gamma_{\mathrm{T}(\mathrm{P})^{+}}=\{\mathrm{a} \varepsilon \mathrm{A}: \mathbf{A}: \mathrm{T}(\mathrm{P}) \vdash \mathrm{Pa}\} ., \\
& \Gamma_{\mathrm{T}(\mathrm{P})^{-}}=\{\mathrm{a} \varepsilon \mathrm{A}: \mathbf{A}: \mathrm{T}(\mathrm{P}) \vdash \mathrm{Pa}\}, \text { and } \\
& \Gamma_{\mathrm{T}(\mathrm{P})}=\left\{\mathrm{a} \varepsilon \mathrm{A}: \mathrm{a} \notin \Gamma_{\mathrm{T}(\mathrm{P})}+\text { and } \mathrm{a} \notin \Gamma_{\mathrm{T}(\mathrm{P})^{-}}\right\} .
\end{aligned}
$$

Thus, we say that predicate $P$ is $T(P)$-observable in $A$ if the set $\Gamma_{\mathrm{T}(\mathrm{P})}$ is empty. $\mathrm{P}$ is then $\mathrm{T}(\mathrm{P})$-observable in $\mathbf{A}$ iff $\mathrm{P}$ is implicitly identifiable on the basis of $\mathrm{T}(\mathrm{P})$ in $\mathbf{A}$. (Rantala 1977)

Clearly auxiliary information makes the P-positive and P-negative sets larger and the uncertainty set smaller. The sets $\left.\Gamma^{+}, \Gamma^{-}, \Gamma, \Gamma_{\mathrm{T}(\mathrm{P})}{ }^{+}, \Gamma_{\mathrm{T}(\mathrm{P})}\right)^{-}, \Gamma_{\mathrm{T}(\mathrm{P})}$ show why it is so easy to confuse the simple observation with an observation dependent on some theory. 
However, simple observation is, in a clear cut sense, dependent on some conceptualization, but not on some theory. (Hintikka 2007, Mutanen 2003)

Above we said that the auxiliary information from the model may not contain P. This means that the inquirer may not ask any question and the model cannot give any answer that includes $\mathrm{P}$. Now, it is possible to restrict the questions and answers to a certain subset $\Delta$ of the non-logical constants of $T(P)$. We say that the set $\Delta$ is the set of observables. We can easily define the P-positive, P-negative and uncertainty sets also in this case. Certainly, the uncertainty set gets larger when we restrict the vocabulary of questions and answers to a certain subset of the vocabulary of $\mathrm{T}(\mathrm{P})$. (Rantala 1977, Niiniluoto 1984,1999)

There are $\mathrm{T}(\mathrm{P})$-dependent observations such that we do not need the whole logical power of the theory $\mathrm{T}(\mathrm{P})$. In these cases it may happen that there is some theory $\mathrm{T}$ that is weaker than $\mathrm{T}(\mathrm{P})$ such that the observation is T-dependent. This induces a hierarchy of theory-dependent observations. Similarly, if predicate $P$ is $T(P)$ observable then sometimes there is some theory $\mathrm{T}$ that is weaker than $\mathrm{T}(\mathrm{P})$ such that $\mathrm{P}$ is T-observable. (See Hintikka 1992 and Grandy 1992.) Similar problems are discussed extensively in the structuralist tradition, see Balzer et. al. 1987.

\section{BASIC RESULTS}

In this chapter we show what role auxiliary information plays in our procedure. And as a basic result we have the following theorem, which can be proved by an easy compactness argument. The following theorems are proved in the papers referenced. However, the proofs convey the information needed to understand the interrogative derivation, so we will reformulate the proofs.

Theorem 1: (Hintikka and Halonen 2005) Let L be a first order language, let $\mathrm{P}$ be a new one-place predicate symbol, let $\mathrm{T}(\mathrm{P})$ be a theory in $\mathrm{L}(\mathrm{P})$ and let $\mathbf{A}$ be a model of $\mathrm{L}(\mathrm{P})$. Let a be an individual in $\mathrm{A}$. Assume that proposition $\mathrm{Pa}$ is $\mathrm{T}(\mathrm{P})$-observable in $\mathbf{A}$. Suppose that the available information from the model is included in the $\mathrm{L}(\mathrm{A})$ diagram $\mathrm{D}$ of $\mathbf{A}$. There is then a formula $\mathrm{F}\left(\mathrm{x}, \mathrm{y}_{1}, \ldots, \mathrm{y}_{\mathrm{n}}\right)$ of $\mathrm{L}$ and $\mathrm{a}_{1}, \ldots, \mathrm{a}_{\mathrm{n}} \varepsilon \mathrm{A}$ such that

(a) $\mathbf{A}: T(P) \vdash F\left(a_{1} a_{1}, \ldots, a_{n}\right)$.

(b) $\mathrm{T}(\mathrm{P}) \vdash \forall \mathrm{x} \forall \mathrm{y} 1 \ldots \mathrm{yn}\left(\mathrm{F}\left(\mathrm{x}, \mathrm{y} 1, \ldots, \mathrm{yn}_{\mathrm{n}}\right)->\mathrm{Px}\right)$.

(c) There are no individual constants in $\mathrm{F}\left(\mathrm{x}_{1}, \mathrm{y}_{1}, \ldots, \mathrm{y}_{\mathrm{n}}\right)$.

(d) $\mathrm{P}$ does not occur in $\mathrm{F}\left(\mathrm{x}, \mathrm{y}_{1}, \ldots, \mathrm{y}_{\mathrm{n}}\right)$. 
PROOF (Hintikka and Halonen 2005): Let D be the diagram of A such that predicate $\mathrm{P}$ does not occur in it. We say that this is the $\mathrm{L}(\mathrm{A})$-diagram of $\mathbf{A}$. So we have

$$
\mathrm{T}(\mathrm{P}) \cup \mathrm{D} F \mathrm{~Pa}
$$

Hence, the set $\mathrm{T}(\mathrm{P}) \cup \mathrm{D} \cup\{\sim \mathrm{Pa}\}$ is inconsistent. By compactness there is a finite conjunction $\chi$ of the sentences of $\mathrm{D}$ such that the set $\mathrm{T}(\mathrm{P}) \cup\{\chi\} \cup\{\sim \mathrm{Pa}\}$ is inconsistent. So for any $\mathbf{B}$, if $\mathbf{B} \vDash \mathrm{T}(\mathrm{P})$, then not:B $\vDash \chi$ or $\mathbf{B} \vDash \mathrm{Pa}$. But this is the same as $\mathrm{T}(\mathrm{P}) \vdash_{\chi->}$ $\mathrm{Pa}$. Let $\mathrm{a}, \mathrm{a}_{1}, \ldots, \mathrm{a}_{\mathrm{n}}$ be individuals from $\mathrm{A}$ that occur in $\chi$. We set $\chi^{\prime}\left(\mathrm{x}, \mathrm{y}_{1}, \ldots, \mathrm{y}_{\mathrm{n}}\right)=$ $\chi\left(x / a_{1} y_{1} / a_{1}, \ldots, y_{n} / a_{n}\right)$. Clearly $\mathbf{A} \vDash \chi^{\prime}\left(a_{1} a_{1}, \ldots, a_{n}\right)$ and because $T(P)$ does not contain the individuals $\mathrm{a}_{1} \mathrm{a}_{1}, \ldots, \mathrm{a}_{\mathrm{n}}$, we have

$$
\mathrm{T}(\mathrm{P}) \vdash \forall \mathrm{x} \forall \mathrm{y}_{1}, \ldots, \mathrm{yn}_{\mathrm{n}}\left[\mathrm{F}\left(\mathrm{x}, \mathrm{y}_{1}, \ldots, \mathrm{yn}_{\mathrm{n}}\right)->\mathrm{Px}\right]
$$

which is the intended result. This is easily generalized to the situation where the available information is any set of sentences of $L(A)$.

The formula $\mathrm{F}$ represents the observational information that is needed in the decision whether the case is $\mathrm{Pa}$ or $\sim \mathrm{Pa}$, and $\mathrm{T}(\mathrm{P})$ represents the presupposed theoretical information. Thus, $\mathrm{T}(\mathrm{P})$ represents the 'known collateral information' that is needed in observation. Notice that from the logical point of view, there is no difference between the sets $T(P)$ and $D$. So we could change the roles of the sets $T(P)$ and D around in Theorem 1, and would have an explicit analysis of the 'known collateral information' that is needed in observation of Pa. (See Hintikka and Harris 1988)

Naturally, we have a similar result for $\sim \mathrm{Pa}$ too. Let the uncertainty set $\Gamma_{\mathrm{T}(\mathrm{P})}$ be empty. In this case, we have for every individual a $\varepsilon \mathrm{A}$ a similar formula $\mathrm{F}$ as in Theorem 1. Now, we may ask if it would be possible to pool these sentences together somehow. If this is possible, we can then find out some kind of definition of P. The following theorem shows that this pooling together is possible with some restrictions. We restrict the available information from the model $\mathbf{A}$ to the $\mathrm{L}(\mathrm{A})-$ diagram of A. (See Rantala 1977, Mutanen 1997)

Theorem 2: (Hintikka and Harris 1991) Let L be a first order language, let $\mathrm{P}$ be a new one-place predicate symbol, let $\mathrm{T}(\mathrm{P})$ be a theory in $\mathrm{L}(\mathrm{P})$ and let $\mathbf{A}$ be a model of $\mathrm{L}(\mathrm{P})$. Let predicate $\mathrm{P}$ be $\mathrm{T}(\mathrm{P})$-observable in $\mathbf{A}$. Assume that the available information 
from $\mathbf{A}$ is included in L(A)-diagram D of A. Assume further that there is a fixed finite upper bound to $\mathrm{n}$ of different formulas $\mathrm{F}$ in Theorem 1. There then exist formulas $\mathrm{F}\left(\mathrm{y}_{1}, \ldots, \mathrm{y}_{\mathrm{n}}\right)$ and $\mathrm{D}\left(\mathrm{x}, \mathrm{y}_{1}, \ldots, \mathrm{yn}_{\mathrm{n}}\right)$ of L such that

(11) A:T(P) $\vdash \exists \mathrm{y}_{1} \ldots \mathrm{y}_{\mathrm{n}} \mathrm{F}\left(\mathrm{y}_{1}, \ldots, \mathrm{y}_{\mathrm{n}}\right)$ and

(12) $\mathbf{A}=\forall \mathrm{y}_{1} \ldots \mathrm{y}_{\mathrm{n}}\left(\mathrm{F}\left(\mathrm{y}_{1}, \ldots, \mathrm{yn}_{\mathrm{n}}\right)->\forall \mathrm{x}\left[\mathrm{Px}<->\mathrm{D}\left(\mathrm{x}, \mathrm{y}_{1}, \ldots, \mathrm{yn}_{\mathrm{n}}\right)\right]\right)$.

PROOF (Hintikka and Harris 1991): From restrictions on $\mathrm{n}$ and the available information it follows by compactness that there are only a finite number $\mathrm{m}$ of candidates for the role of $\mathrm{F}$ for different a $\varepsilon \mathrm{A}$. Let them be

(13) $F_{i}\left(x, y_{1}, \ldots, y_{n}\right) i=1, \ldots, m$.

Each a $\varepsilon$ A satisfies the condition for some $F_{i}$ and for some $a_{i 1}, \ldots, a_{i n}$. These individuals can be chosen independently of a. So we have

(14) A:T(P) $\vdash \exists y_{11 \ldots} \ldots y_{1 n} \exists y_{21} \ldots y_{2 n} \ldots \exists y_{m 1} \ldots y_{m n} \forall x \vee_{i=1} \mathrm{~m}_{i}\left(x, y_{i 1}, \ldots, y_{i n}\right)$.

For every $\mathrm{F}_{\mathrm{i}}$ we have $\mathbf{A}: \mathrm{T}(\mathrm{P}) \vdash \mathrm{F}_{\mathrm{i}} \rightarrow \mathrm{Pa}$ or $\mathbf{A}: \mathrm{T}(\mathrm{P}) \vdash \mathrm{F}_{\mathrm{i}} \rightarrow>\mathrm{Pa}$, so we can formulate the following sets

(15) $\Sigma^{+}=\left\{F_{i}: \mathbf{A}: T(P) \vdash F_{i}->P a\right\}$ and

(16) $\Sigma^{-}=\left\{F_{i}: \mathbf{A}: T(P) \vdash F_{i}->\sim P a\right\}$.

Let $\operatorname{crd}\left(\Sigma^{+}\right)=\mathrm{p}$ and $\operatorname{crd}\left(\Sigma^{-}\right)=\mathrm{r}$, where $\operatorname{crd}(\mathrm{A})$ is the cardinal of set $\mathrm{A}$. In this case, $\mathrm{p}$ $+\mathrm{r}=\mathrm{m}$. Theorem 1 gives us the following

(17) $\mathrm{T}(\mathrm{P}) \vdash \forall \mathrm{y}_{1} \ldots \mathrm{y}_{\mathrm{n}} \forall \mathrm{x}\left[\mathrm{F}^{+}\left(\mathrm{x}, \mathrm{y}_{1}, \ldots, \mathrm{y}_{\mathrm{n}}\right)->\mathrm{Px}\right]$,

where $\mathrm{F}^{+} \varepsilon \Sigma^{+}$. So we have

(18) $\mathrm{T}(\mathrm{P}) \vdash \forall \mathrm{y}_{1} \ldots \mathrm{y}_{\mathrm{n}} \forall \mathrm{x}\left[\mathrm{\vee}_{\mathrm{i}=1} \mathrm{pF}_{\mathrm{i}}^{+}\left(\mathrm{x}, \mathrm{y}_{1}, \ldots, \mathrm{y}_{\mathrm{n}}\right)->\mathrm{Px}\right]$, 
where each $\mathrm{F}_{\mathrm{i}}^{+} \varepsilon \Sigma^{+}(\mathrm{i}=1, \ldots, \mathrm{p})$. Similarly, we have

(19) $\mathrm{T}(\mathrm{P}) \vdash \forall \mathrm{y}_{1} \ldots \mathrm{y}_{\mathrm{n}} \forall \mathrm{x}\left[\vee_{\mathrm{i}=1^{\mathrm{r}}} \mathrm{F}_{\mathrm{i}}-\left(\mathrm{x}, \mathrm{y}_{1}, \ldots, \mathrm{y}_{\mathrm{n}}\right)->\sim \mathrm{Px}\right]$,

where each $\mathrm{F}_{\mathrm{i}^{-}} \varepsilon \Sigma^{-}(\mathrm{i}=1, \ldots, \mathrm{r})$. By definition, we have

(20) $\mathrm{T}(\mathrm{P}) \vdash \forall \mathrm{y}_{1} \ldots \mathrm{y}_{\mathrm{n}} \forall \mathrm{x}\left[\sim \mathrm{F}_{\mathrm{i}}^{+}\left(\mathrm{x}, \mathrm{y}_{1}, \ldots, \mathrm{y}_{\mathrm{n}}\right)->\mathrm{F}_{\mathrm{j}}-\left(\mathrm{x}, \mathrm{y}_{1}, \ldots, \mathrm{y}_{\mathrm{n}}\right)\right]$

for every $\mathrm{F}_{\mathrm{i}}^{+} \varepsilon \Sigma^{+}$and for every $\mathrm{F}_{\mathrm{j}}{ }^{-} \varepsilon \Sigma$ - Thus, we have

(21) $\mathrm{T}(\mathrm{P}) \vdash \forall \mathrm{y}_{1} \ldots \mathrm{y}_{\mathrm{n}}\left(\forall \mathrm{x} \vee_{\mathrm{i}=1} \mathrm{~m}^{\mathrm{m}} \mathrm{F}_{\mathrm{i}}\left(\mathrm{x}, \mathrm{y}_{1}, \ldots, \mathrm{y}_{\mathrm{n}}\right)->\forall \mathrm{x}\left[\sim \vee_{\mathrm{i}=1} \mathrm{p} \mathrm{F}_{\mathrm{i}}^{+}\left(\mathrm{x}, \mathrm{y}_{1}, \ldots, \mathrm{y}_{\mathrm{n}}\right)->\right.\right.$ $\left.\left.\vee_{j}=1^{r} F_{j}\left(x, y 1, \ldots, y_{n}\right)\right]\right)$.

Now from (18), (19) and (21) we get

(22) $\mathbf{A} \vDash \forall \forall \mathrm{y}_{1} \ldots \mathrm{y}_{\mathrm{n}}\left(\forall \mathrm{x} \vee_{\mathrm{i}=1} \mathrm{~m}^{\mathrm{m}} \mathrm{F}_{\mathrm{i}}\left(\mathrm{x}, \mathrm{y}_{1}, \ldots, \mathrm{y}_{\mathrm{n}}\right)->\forall \mathrm{x}\left[\mathrm{Px}<->\vee_{\mathrm{i}=1} \mathrm{p} \mathrm{F}_{\mathrm{i}}^{+}\left(\mathrm{x}, \mathrm{y}_{1}, \ldots, \mathrm{y}_{\mathrm{n}}\right)\right]\right)$.

And if we put $\mathrm{F}\left(\mathrm{y}_{1}, \ldots, \mathrm{yn}_{\mathrm{n}}\right)=\forall \mathrm{x} \quad \mathrm{V}_{\mathrm{i}=1^{\mathrm{m}}} \mathrm{F}_{\mathrm{i}}\left(\mathrm{x}, \mathrm{y}_{1}, \ldots, \mathrm{y}_{\mathrm{n}}\right)$ and $\mathrm{D}\left(\mathrm{x}, \mathrm{y}_{1}, \ldots, \mathrm{yn}_{\mathrm{n}}\right)=\vee_{\mathrm{i}=1} \mathrm{p}$ $\mathrm{F}_{\mathrm{i}}{ }^{+}\left(\mathrm{x}, \mathrm{y}_{1}, \ldots, \mathrm{y}_{\mathrm{n}}\right)$, we get the intended result.

We can generalize theorem 2 by allowing the available information from the model to be any fixed set $\mathrm{K}$ of $\mathrm{L}(\mathrm{A})$-sentences such that $\mathbf{A}=\mathrm{K}$. In this case, we need one more restriction: There must be a fixed finite upper bound to the quantificational depth of the different formulas $\mathrm{F}$ in Theorem 1.

The proof shows clearly how the experimental information needed in the process of identification is constructed out of the reality. However, at the same we can see the role of the theoretical information that is needed in the process. Moreover, the proof shows how the empirical and theoretical information are interconnected. (See Hintikka 2007.) 
If the assumption of Theorem 2 holds in every model $\mathbf{A}$ of the theory $\mathrm{T}(\mathrm{P})$, then by compactness we have that $\mathrm{P}$ is finitely definable in $\mathrm{T}(\mathrm{P})$. (See Rantala 1977 and Chang and Keisler 1973.)

\section{MEASURABILITY}

In measuring a concept, the question is whether the theory together with a suitable set of observations can determine the value of the concept. We say that predicate $\mathrm{P}$ is measurable on the basis of $\mathrm{T}(\mathrm{P})$ in $\mathbf{A}$ if $\mathrm{T}(\mathrm{P})$ together with suitable observations from $\mathbf{A}$ can determine the value of $\mathrm{P}$ for every individual $\mathrm{a}$ in the domain $\mathrm{A}$. It is usual to suppose that a theory of measurement has some kind of invariance. This means that the truth value of statements is invariant under (similarity) transformations. (Hintikka 1992, 2007, Hintikka and Halonen 1994, 2005)

In the following we show that our notion of (explicit) identifiability has the desired properties.

First we present the "preservation property" of explicit identifiability. This basic property of explicit identifiability is proved similarly to its counterpart in the theory of definitions (cf. proof of Theorem 1 and 2).

Theorem 3: (Rantala 1977) Let A be a model of T(P). The following conditions are then equivalent.

(i) $\mathrm{P}$ is explicitly identifiable on the basis of $\mathrm{T}(\mathrm{P})$ in $\mathbf{A}$ (cf. definition above).

(ii) Let $\mathbf{B}$ be any expansion of $\mathbf{A} \uparrow \mathrm{L}$ to a model of $\mathrm{T}(\mathrm{P})$ and let $\mathrm{f}$ be any automorphism of $\mathbf{A} \uparrow \mathrm{L}$ such that $\mathrm{f}\left(\mathrm{a}_{1}\right)=\mathrm{a}_{1}, \ldots, \mathrm{f}\left(\mathrm{a}_{\mathrm{n}}\right)=\mathrm{a}_{\mathrm{n}}$, then $\mathrm{f}$ fixes the interpretation of $\mathrm{P}$ in $\mathrm{B}$ i.e. $\mathrm{f}\left(\mathrm{PB}^{\mathrm{B}}\right)=\mathrm{P}^{\mathrm{B}}$.

This theorem says that the set determined by the predicate $\mathrm{P}$ is fixed in every automorphism that fixes the point-wise reference points of the quasidefinition. Theorem 3 proves that there can be only one interpretation of $\mathrm{P}$ in the extended model $\left(\mathbf{A}, \mathrm{a}_{1}, \ldots, \mathrm{a}_{\mathrm{n}}\right)$. Thus, Theorem 3 gives Beth-property to the notion of explicit identifiability. The condition that every automorphism of $\mathbf{A} \uparrow \mathrm{L}$ fixes the point-wise reference point individuals $\mathrm{a}_{1}, \ldots, \mathrm{a}_{\mathrm{n}}$ means that these points are definable in $a$ generalized sense (Hodges 1993).

In theory of measurement it is usually supposed that measurement is explicated by a numerical function. We can easily generalize the notion of identifiability of a predicate symbol to identifiability of a function symbol. Let $\mathrm{L}$ be a first order language, let $\mathrm{F}$ be a new function symbol, let $\mathrm{T}(\mathrm{F})$ be a theory in $\mathrm{L}(\mathrm{F})$ and let $\mathbf{A}$ be a 
model of $\mathrm{L}(\mathrm{F})$. We can then say that $\mathrm{F}$ is explicitly identifiable on the basis of $T(F)$ in $A$ if there is a formula $\mathrm{D}\left(\mathrm{x}, \mathrm{z}, \mathrm{y}_{1}, \ldots, \mathrm{y}_{\mathrm{n}}\right)$ of $\mathrm{L}$ and individuals $\mathrm{a}_{1}, \ldots, \mathrm{a}_{\mathrm{n}}$ in A such that

$\mathbf{A}: \mathrm{T}(\mathrm{F}) \vdash \forall \mathrm{xz}\left[\mathrm{Fx}=\mathrm{z}<->\mathrm{D}\left(\mathrm{x}, \mathrm{z}, \mathrm{a}_{1}, \ldots, \mathrm{a}_{\mathrm{n}}\right)\right]$

And the following admissibility condition has to be true in $\mathbf{A}$

$\forall x \exists=1 \mathrm{zD}\left(\mathrm{x}, \mathrm{z}, \mathrm{a}_{1}, \ldots, \mathrm{a}_{\mathrm{n}}\right)$

On the problem of numerical presentation I refer to Suppes 1969. We have shown that explicit identifiability has the desired properties. So the notion of explicit identifiability can be seen as one explication of the notion of measurability. (See Suppe 1989 and Hintikka 1991.)

We say that $\mathrm{P}$ is explicitly definable in $\mathrm{T}(\mathrm{P})$, if there is a formula $\mathrm{D}(\mathrm{x})$ of $\mathrm{L}$ such that

(23) $\mathrm{T}(\mathrm{P}) \vdash \forall \mathrm{x}[\mathrm{Px}<->\mathrm{D}(\mathrm{x})]$

We now have following theorem.

Theorem 4: (Hodges 1993) Let $\mathrm{T}(\mathrm{P})$ be a complete theory in $\mathrm{L}(\mathrm{P})$ and let $\mathbf{A}$ be a model of $\mathrm{T}(\mathrm{P})$. The following conditions are then equivalent.

(i) $\mathrm{P}$ is explicitly definable in $\mathrm{T}(\mathrm{P})$.

(ii) Let $\mathbf{B}$ be any expansion of $\mathbf{A} \uparrow \mathrm{L}$ to a model of $\mathrm{T}(\mathrm{P})$ and let $\mathrm{f}$ be any automorphism of $\mathbf{A} \uparrow \mathrm{L}$, then f fixes the interpretation of $\mathrm{P}$ in $\mathbf{B}$.

Proof: See Hodges (1993).

If $\mathrm{T}(\mathrm{P})$ is not a complete theory, then from condition (ii) of $\mathrm{T} 4$ it follows that $\mathrm{P}$ is piecewise definable in $\mathrm{T}(\mathrm{P})$. From Theorem 3 and Theorem 4 we can see that explicit identifiability is a weaker notion than explicit definability. This follows from the fact that automorphisms of $\mathrm{A} \uparrow \mathrm{L}$ that fix reference points are included in all automorphisms of $\mathbf{A} \uparrow \mathrm{L}$. 
The following theorem shows the difference between the notions of explicit identifiability and restricted definability.

Theorem 5: (Rantala 1977) Let $\mathbf{A}$ be an infinite model of $\mathrm{T}(\mathrm{P})$ and let the cardinality of $\mathbf{A}$ be a. The following condition is then equivalent to condition (ii) in Theorem 3 .

(iii) The number of different expansions of $\mathbf{A} \uparrow \mathbf{L}$ that are isomorphic to $\mathbf{A}$ is at most a.

Proof: See Rantala 1977.

Now again we are between two different notions. If we do not use any information from the model, then explicit identifiability reduces to explicit or piecewise definability. If there is no restriction on information from the model, then $\mathrm{T}(\mathrm{P})$ becomes redundant and we have definability in a model with parameters. If this happens in every model of $\mathrm{T}(\mathrm{P})$, then $\mathrm{P}$ is restrictedly definable in $\mathrm{T}(\mathrm{P})$. (Rantala 1977)

But we are now between these points. We get reference point individuals from observations, so we get them from simple observation or from some measurements which have been performed before. If we get them from simple observation, we say that they are directly or ostensively defined. So these individuals are known individuals, (See Hintikka 2007.) and we have an explicit definition of P, not in language $\mathrm{L}$, but in the extended language $\mathrm{L}\left(\mathrm{c}_{1}, \ldots, \mathrm{c}_{\mathrm{n}}\right)$ where $\mathrm{c}_{1}, \ldots, \mathrm{c}_{\mathrm{n}}$ are distinguished, known individuals in the model (see note after Theorem 3 ).

\section{Concluding remarks}

We have seen that there are different notions of observability. Basically, observation means observation by human senses, but in the scientific process this is not enough. We use some observational and experimental technology in observations, and so observations become theory dependent (or at least technology dependent). This means that measurements are allowed in observations, and that measurements are special cases of observations (cf. Suppe 1989). In our treatment, measurements are always dependent on some theory. (See Hintikka 1992, Grandy 1992 and Carrier 1994.) Our notion of measurability becomes exact when the set of available information from the model is specified.

We have inquired about the logical nature of notions of observability and measurability (identifiability). Theorems 1 and 2 show that it is logically possible to find out some kind of definition of a predicate from single observations. Theorems 3 , 
4 and 5 show interesting interconnections between the notions of measurability (identifiability) and definability.

In some cases, explicit identifiability as an explication of measurability is too strong. So we define the following notion. We say that predicate $\mathrm{P}$ is conditionally identifiable on the basis of $T(P)$ in $A$ if there are formulas $\mathrm{F}(\mathrm{x})$ and $\mathrm{D}\left(\mathrm{x}, \mathrm{y}_{1}, \ldots, \mathrm{yn}_{\mathrm{n}}\right)$ of $\mathrm{L}$ and individuals $\mathrm{a}_{1}, \ldots, \mathrm{a}_{\mathrm{n}}$ in $\mathrm{A}$ such that

$\mathbf{A}: \mathrm{T}(\mathrm{P}) \vdash \forall \mathrm{x}\left(\mathrm{F}(\mathrm{x})->\left[\mathrm{Px}<->\mathrm{D}\left(\mathrm{x}, \mathrm{a}_{1}, \ldots, \mathrm{a}_{\mathrm{n}}\right)\right]\right)$

Conditional identifiability has similar properties as conditional definability. We say that $\mathrm{P}$ is restrictedly measurable on the basis of $\mathrm{T}(\mathrm{P})$ in $\mathbf{A}$ iff $\mathrm{P}$ is conditionally identifiable on the basis of $\mathrm{T}(\mathrm{P})$ in $\mathbf{A}$. This means that we can apply this measuring procedure only to the individuals which have the property $\mathrm{F}$. If an individual does not have the property $\mathrm{F}$, then this measuring procedure does not apply. So the formula $\mathrm{F}$ gives us the set of measurable individuals. This situation is usual in actual methodology of science. (Rantala 1977 and Hintikka 1991)

We have seen that different restrictions in the available information give different notions of observation. For example, Hintikka and Harris (1988) show that implicit identifiability with relatively weak assumptions implies explicit identifiability. This shows that logical study of this information is of philosophical interest. To understand what kind of restrictions are reasonable we should study the logic of experiments (Hintikka 1988).

We have defined the notion of measurability in a strong sense. However, the definition is well justified because of the conceptual and theoretical clarity. Moreover, it has been connected to the notion of identifiability, which has been a central notion in the methodology of the experimental and empirical sciences. However, at the same the consideration shows (implicitly) that uses of the notion of measurability that use, for example, several kinds of questionnaires have only some kind of metaphorical connection to the measurability considered in this paper. (See Hacking 1999.) Analysing such approaches fully requires an entire analysis of its own. 


\section{Bibliography}

Alston, W P, 1993, The Reliability of Sense Perception, Cornell University Press.

Balzer W, Moulines C. U and Sneed J. D., 1987, An Architectonic for Science, The Structuralist Program; D. Reidel Publishing Company, Dordrecht.

Carrier M, 1994, The Completeness of Scientific Theories On the Derivation of Empirical Indicators within a Theoretical Framework: The Case of Physical Geometry, Kluwer Academic Publishers, Netherlands.

Chang C.C and Keisler H.J, 1973, Model Theory, North-Holland, Netherlands.

Earman J (ed.), 1992, Inference, Explanation, and Other Frustrations, Essays in the Philosophy of Science; University of California Press, Oxford.

Grandy R.E, 1992, Theories of Theories: A View from Cognitive Science; in Earman (1992) p.216-233.

Hacking, I, 1983, Representing and Interventing, Cambrige Univeristy Press

Hacking, I, 1999, The Social Construction of What?, Harvard University Press

Hintikka J, 1991, Towards a General Theory of Identifiability. In J.H. Fetzer, D.Shatz and G. Schlesinger (eds.): Definitions and Definability: Philospohical Perspectives, p. 161-183; Kluwer Academic Publishers, Netherlands.

Hintikka J, 1988 What Is The Logic of Experimental Inquiry; in Synthese vol. 74, p. 173-190, Kluwer Academic Publishers, Netherlands.

Hintikka J, 1992, Theory-Ladenness of Observations as a Test Case of Kuhn's Approach to Scientific Inquiry, in PSA 1992, vol 1, p. 277-286.

Hintikka, J, 2007, Socratic Epistemology, Cambridge University Press

Hintikka J and Halonen I, 1994 Quantum Logic as a Logic of Identification, in Patric Suppes Scientific Philosopher, Humpreys P (ed.), p. 125-143, Kluwer Academic Publishers, Netherlands.

Hintikka, J and Halonen I, 2005, Toward a Theory of the Process of Explanation, Synthese 143. 
Hintikka, J, Halonen, I, and Mutanen, A, 2002, Interrogative Logic as a General Theory of Reasoning, teoksessa R.H. Johnson and J. Woods (toim.), Handbook of Practical Reasoning, Kluwer Academic, Dordrecht

Hintikka J and Harris S, 1988, On The Logic of Interrogative Inquiry, in PSA 1988 vol 1, p. 233-240.

Hodges W, 1993, Model Theory, Cambridge University Press, Cambridge.

Mutanen, A, 1997, Theory of Identifiability, in Matti Sintonen (toim.) Knowledge and Inquiry: Essays on Jaakko Hintikka's Epistemology and Philosophy of Science, Rodopi, Amsterdam

Mutanen, A, 2003, Learning with Positive Information (abstract), Volume of Abstracts of $12^{\text {th }}$ International Congress of Logic, Methodology and Philosophy of Science

Mutanen, A., 2004, From Computation to Truth via Learning, Helsinki

Niiniluoto, I, 1982, Remarks on the Logic of Perception, in Niiniluoto, I. \& E. Saarinen (eds.), Intensional Logic: Theory and Applications, Acta Philosophica Fennica 35, Helsinki.

Niiniluoto, I, 1984, Is Science Progressive?, Reidel

Niiniluoto, I, 1999, Critical Scientific Realism, Oxford University Press

Rantala V, 1977, Aspects of Definability, North-Holland; Amsterdam.

Rantala, V, 1991, Definitions and Definability, In Fetzer, J H, Shatz, D and Schlesinger (eds.) Definitions and Definability: Philosophical Perspectives. Kluver Academic Publishers

Sintonen, M, 2006, From the Logic of Questions to the logic of Inquiry, in Auxier, R E and Hahn, L E (eds.) The philosophy of Jaakko Hintikka, Library of Living Philosophers vol. XXX, Open Court.

Suppe F, 1989, The Semantic Conseption of Theories and Scientific Realism, University of Illinois Press, Urbana and Chicago.

Suppes P, 1965, Logics Appropriate to Empirical Theories; in Symposium on the Theory of Models, North-Holland Publishing Company, Amsterdam. 
Suppes P, 1969, Studies the Methodology and Foundation of Science; D. Reidel, Dordrecht-Holland.

Žanić, J, 2008, Reality Check: On the Solvability of the Realism/Constructivism Dispute in Ontology, Synthesis Philosophica, Vol.23 No.1/2008 